
Fernández, O., Habermüller, M., and Grasemann, B., 2020, Hooked on salt: Rethinking Alpine tectonics in Hallstatt (Eastern Alps, Austria): Geology, v. 49, https://doi.org/10.1130/G47981.1

\section{DIGITAL OUTCROP}

Mapping of inaccessible parts of the Echernwand was supported by photogrammetric construction of a 3D model (virtual outcrop). 115 pictures of the wall were captured with a DJI Mavic 2 pro drone equipped with a Hasselblad L1D-20c camera with 20 Megapixel and a 1“ CMOS-sensor. Using a Structure from Motion algorithm (Agisoft Metashape Professional v. 1.6.2., www.agisoft.com) a dense point cloud with 29745717 points was calculated. From the dense cloud and the original picture information a georeferenced, textured 3D model with 4491615 faces was computed. The 3D model was exported to an orthomosaic $(10 \mathrm{~cm} / \mathrm{pixel}$ resolution, Fig. 3A) and a Wavefront (.obj) file, which was further processed in the software LIME 2.0 (virtualoutcrop.com/lime) in order to measure spatial orientations of bedding and faults. A 3D PDF is included as Data Repository DR1.

\section{CROSS-SECTION CONSTRUCTION AND RESTORATION}

Cross-section construction and restoration were performed in Move 2019.1 software (Petex, https://www.petex.com/products/move-suite/). The section is oriented in a NNW-SSE to capture both the regional structure (E-W trending folds) and the relationship of the Hallstatt diapir with its southeastern flank. This orientation is consistent with that proposed by Linzer et al. (1995) for balanced cross-sections of the NCA and no major strike-slip features are cross-cut by the section, supporting the assumption of plane strain. Nonetheless, significant strike-slip experienced by the diapir during post-Jurassic times (Arnberger, 2006; Schmid, 2009; Schorn and Neubauer, 2014) implies that mini-basins of Triassic limestones formed above the diapir are likely to have moved into, out of, or across the plane of section after the Triassic.

Data was projected onto the section from a distance of less than $1 \mathrm{~km}$ along the local structural axes. Mapped geological contacts up to within $10 \mathrm{~km}$ of the section were used to constrain the thickness of units, in particular that of the Dachstein Fm on the southern flank of the Hallstatt diapir. Previous sections constrained with mining information (Mandl, 2012; 
Schorn and Neubauer, 2014) and information provided verbally by Salinen AG were used to constrain the structure of the diapir at depth.

Restoration was performed by unfolding blocks with the flexural-slip algorithm in Move (2D Kinematic module). The dimension of the diapir in restored state was estimated by placing the unfolded blocks of Triassic and Jurassic sediments side by side, assuming no out-of-plane motion, and allowing for partial allochthony of the diapir on its northern flank. Given the potential obliquity of the section with the regional transport direction and potential out-ofplane motion of the Haselgebirge Fm within the diapir due to strike-slip deformation (Schorn and Neubauer, 2014), it is considered that the restored cross-sectional area of the diapir is an upper estimate. The bathymetry of the restored section reflects the development of shallowwater conditions over the Hallstatt diapir and coeval deeper water conditions laterally. Eroded sections of Triassic and Jurassic sediments have been estimated to complete the cross-section. 